\title{
Use of high-speed water flows for accelerated mechanical modelling of erosive wear of con- crete surfaces
}

\author{
Libor Sitek ${ }^{1, *}$, Petr Hlaváček ${ }^{1}$ and Lenka Bodnárová $^{2}$ \\ ${ }^{1}$ Institute of Geonics of the CAS, Studentská 1768, 70800 Ostrava, Czech Republic \\ ${ }^{2}$ Brno University of Technology, Faculty of Civil Engineering, Veveři 331/95, 60200 Brno, Czech \\ Republic
}

\begin{abstract}
The article deals with an unconventional way of simulating the erosion of concrete surfaces by means of high-speed water flows. The proposed method allows the use of short-term experiments to predict the future failure of concrete elements in specific concrete mixtures exposed in practice to the action of fast-flowing fluids, whether as regards sewers, overfalls of water reservoirs, inlet channels of retention reservoirs, etc. The article shows results of experiments on disintegration of the surface layer of model concrete test specimens of various physical-mechanical properties that were exposed to various types of high-speed water flows. It has been demonstrated that the application of high-speed water flows significantly accelerates the degradation process of the surface layers. This simulation of the real situation can considerably shorten the time needed for the development and testing of new erosion-resistant construction elements.
\end{abstract}

Keywords: high-speed water flow, cement composites, erosive wear, abrasion, abrasive material, short-time erosion test

\section{Introduction}

Concrete surfaces exposed to the long-term contact with fast-flowing polluted water (more than $5 \mathrm{~m} . \mathrm{s}^{-1}$ ) are affected by gradual erosion and abrasive wear caused by the presence of small particles in the water flow. In addition, at high flow rates (more than $15 \mathrm{~m} . \mathrm{s}^{-1}$ ), cavitation occurs as another destruction mechanism. Due to these effects, surfaces of concrete structures are rapidly degraded by initiation of small caverns. Caverns quickly expand and depth failure with consequent concrete breakage occurs. This particular complex type of degradation was found in sewers, water supply channels in water treatment plants, waterpower plants, especially in chutes in dam overfalls during floods, but also in overfalls of weirs, dam crests or inlet channels and stilling basins of retention reservoirs.

Development of resistant concrete mixtures and determination of suitable surface treatments to make construction elements resistant to the flowing liquids has been the subject of research for decades. The disadvantage is that the resistance prediction of these elements

\footnotetext{
* Corresponding author: libor.sitek@ugn.cas.cz

Reviewers: Anna Mičietová, Miroslav Müller
} 
is complicated and too unreliable, as the degradation of real structures often occurs in a period of several years. The impossibility of verifying the resistance of construction components to erosive and abrasive wear of the flowing fluids in real time complicates the development of new resistant mixtures. At present, requirements for concrete quality are primarily solved by the demand for the minimum concrete strength class, the maximum water/cement ratio and the aggregate type. As there is no precise methodology for testing the influence of the flowing fluids on the surface of concrete structures, it is impossible to test the proposed formulae in laboratories and use them in practice.

Many years of experience with the disintegration of cement composites using the highspeed water jets encouraged us to use this unconventional technology for an accelerated mechanical simulation of the degradation process of concrete surfaces. Thus, the main goal of the research is the effort to find a suitable method providing sufficient information about the resistance of the concrete against the violation by the flowing liquids in a short time. The method based on the action of high-speed water jet on surface structures of concrete should authentically simulate the real situation.

\section{High-speed water jets}

High-speed water jet technology is able to disintegrate even the hardest materials due to high energy transmitted to an extremely small area (see e.g. [1]). Using water jets, there is no mechanical tool-material interaction in the process of disintegration. The maximum temperature of the jet does not exceed $70^{\circ} \mathrm{C}$ and zones in the area of the cut are thus unaffected by the heat. No thermal interference of the material to be cut as well as universality of the jet application are the greatest benefits of the abrasive water jets. The erosion capability of the jets is widely used in modern industry. The water jet technology achieved significant progress in the last decades in applications such as cutting of wide range of materials, surface cleaning, removal of surface layers and repair of concrete structures. Nowadays, a number of commercial high pressure systems are available on the market, some of them generating pressures up to $700 \mathrm{MPa}$, other delivering up to hundreds of litres of water per minute. Water jet cutting and/or cleaning equipment, except the pump, is lightweight and the whole cutting or cleaning process can be easily automated [2].

The water jet technology is also very advantageous for the removal of deteriorated concrete layers from buildings and structures [3]. The first serious concept for the use of water jets for concrete removal and cleaning (i.e. hydrodemolition) was probably that of [4]. The first commercial hydrodemolition unit was finally developed and introduced 10 years later [2]. High-speed water jet technology has been used for the removal of damaged concrete in civil engineering since the 80 's of $20^{\text {th }}$ century [5]. The water jets are able to remove the damaged layer selectively without introducing any additional cracks into the construction (in contrast to traditional technologies like jackhammering, grit blasting, milling, etc.). Moreover, adhesion strength of coatings applied on surfaces prepared by water jets comply with values specified in relevant standards concerning the concrete surface treatment prior to repair [6]. Several articles deal with the interaction of water jets with concretes (e.g. [2], [79]) and steel-fibre reinforced concretes [10-11], while other describe the simulation of erosion of concretes in hydraulic structures in different ways (e.g. [12-14]). In [15], acoustic emission sensing technique is proposed for on-line monitoring of hydro-abrasive erosion. Wear particles originated from erosion of concrete after the application of high velocity water flow are then studied in the work [16].

Based on previous experience, the following types of jets were selected for testing the erosion damage that simulated the effects of fast-flowing liquids on concrete surfaces: 


\subsection{Plain water jet}

The jet (Fig. 1a) is generated by the change of the pressure energy of water to the kinetic energy by the acceleration of the water flow within the nozzle. The maximum pressures currently used for the generation of the plain water jets are up to $700 \mathrm{MPa}$. This jet type is suitable for cutting of softer materials (rubber, paper, wood, plastic, etc.), cleaning of materials from paints and coatings and removal of surface layers.

When a steady continuous, inviscid and incompressible liquid jet impinges on a flat rigid surface, the maximum pressure (according to Bernoulli's equation) at the point of impact equals the stagnation pressure $p_{\mathrm{s}}$, given by:

$$
p_{\mathrm{s}}=\frac{1}{2} \rho V_{0}^{2},
$$

where $p_{\mathrm{s}}$ is the stagnation pressure, $\rho$ the density of the liquid (water) and $V_{0}$ the velocity of the impinging jet [17]. Despite the high velocity of the impinging jet (typically $700 \mathrm{~m} \cdot \mathrm{s}^{-1}$ ) and thus the high stagnation pressure, the force effects of the jet on the impact area are relatively small due to the limited area of the water flow impact. For example, at the pressure of $250 \mathrm{MPa}$ and diameter of $0.33 \mathrm{~mm}$, the final measured force on the impact area was only around $40 \mathrm{~N}$ [18].

(a)

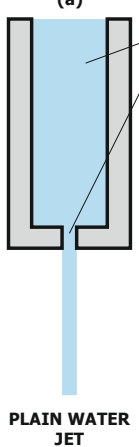

(b)

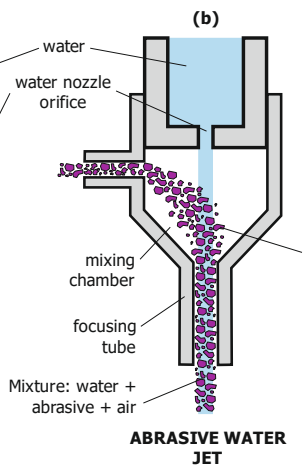

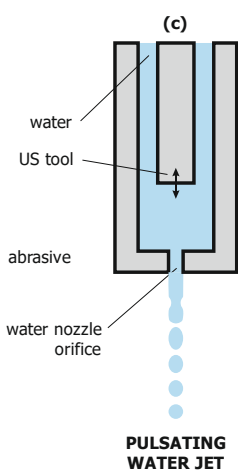

Fig. 1. Types of water jet used in experiments

\subsection{Abrasive water jet}

Cutting performance of the plain water jet can be significantly increased by adding abrasive particles into the jet. They are added into the jet downstream the water nozzle in a mixing chamber and consequently focused and accelerated in a focusing tube (Fig. 1b). Pressures up to $420 \mathrm{MPa}$ are commonly used to generate this type of the jet. Almandine garnet or olivine concentrates with grain size of about $0.2 \mathrm{~mm}$ are usually used as abrasive materials [19]. With a single water jet based system, several machining operations can be performed on a wide range of materials with various geometries. The abrasive water jet can cut, drill, turn, mill, etc. difficult-to-machine materials such as composites, structural ceramics, high-strength alloys, glass, rocks, etc.

Despite the significantly higher cutting performance compared to the plain water jet, the impact forces of the abrasive water jet remain similar. The impact force of the abrasive water jet was measured to be about $30 \mathrm{~N}$ at the water pressure of $300 \mathrm{MPa}$, with the nozzle diameter of $0.33 \mathrm{~mm}$ and mass flow rate of $300 \mathrm{~g} \cdot \mathrm{min}^{-1}$ of the Australian garnet with grain size of 80 mesh (i.e. mean grain size of $0.18 \mathrm{~mm}$ according to [19]). The water medium only accelerates and transports abrasive particles to the area of interaction with the material. Mixing of the abrasive with the water jet by the flow through the abrasive head and acceleration in the 
focusing tube leads to certain losses in energy. The resulting force is thus slightly lower compared to the forces measured in the plain water jet. The velocity of individual abrasive particles in the high-speed water jet at the outlet from the focusing tube primarily depends on the grain size, water pressure in front of the nozzle, concentration of abrasive grains in the jet and the stand-off distance from the nozzle exit [20]. E.g. in the paper [21], the average particle velocity measured in the jet with the water nozzle of $0.25 \mathrm{~mm}$ at the water pressures of 80-140 MPa was 117-161 m.s.

\subsection{Pulsating water jet}

One of possible methods how to significantly improve the performance of the plain water jet without the addition of abrasives is the method using a pulsating water jet (Fig. 1c). The impact pressure on a target generated by a bunch of water is considerably higher than the stagnation pressure of the corresponding continuous plain water jet [22, 23].

If a drop or a slug of liquid strikes the same target, the initial impact pressure will be much higher. The so-called waterhammer pressure developed by the impact of the jet with a flat head on a rigid plane surface can be derived by a one-dimensional (Rankine-Hugoniot) analysis, as:

$$
p_{\mathrm{i}}=\rho V_{0} C_{0},
$$

where $C_{0}$ is the speed of sound (sonic velocity) in a liquid (water) and $V_{0}$ is the velocity of the jet. The equation (2) represents the simplest approximation to the maximum impact pressure rise developed in a liquid-solid collision. After very short time (the duration of the impact pressure is affected by the size and shape of the drop), the pressure drops to the stagnation pressure $p_{\mathrm{s}}$. In the pulsating jet, the impact pressure is amplified (see [24])

$$
Z=\frac{p_{\mathrm{i}}}{p_{\mathrm{s}}}=\frac{2 C_{0}}{V_{0}}=\frac{2954}{V_{0}},
$$

where $p_{\mathrm{i}}$ is the impact pressure, $p_{\mathrm{s}}$ is the stagnation pressure. Velocities of the continuous jets generally do not exceed $700 \mathrm{~m} . \mathrm{s}^{-1}$. Thus, the impact pressure of the pulsating jet can be at least 4 times higher at the same velocity. Therefore, significant improvement in cutting performance is expected. Moreover, additional effects such as fatigue failure of the target material due to the cyclic loading contribute to more effective performance of the pulsating water jets.

An increase in the impact force is given, for example, in [17]. The force of the water jet generated at the pressure of $20 \mathrm{MPa}$, the diameter of $1.98 \mathrm{~mm}$, and the stand-off distance of $40 \mathrm{~mm}$ was increased from about $120 \mathrm{~N}$ to $400 \mathrm{~N}$.

\section{Experiments}

Suitability of the above mentioned types of water jets for an accelerated mechanical simulation of the surface layer degradation of selected cement composites by the combined wear was evaluated on the basis of experimental tests. The jets used, including their parameters and the range of values set during the experiments, are shown in Table 1.

Because of large-scale experimental work, all experiments were divided into two stages. During the first stage, a suitable configuration of working parameters of the high-speed water jet to simulate the erosion wear of concretes by the flowing water was determined. In the second stage, the tests were focused on comparing two different types of concretes and their resistance to fast-flowing water. Particular settings of parameters of the water jet and cutting devices used during individual stages are listed in the text. 
Table 1. Tested jets and the range of parameters used in experiments

\begin{tabular}{|c|c|c|c|c|c|c|c|}
\hline $\begin{array}{c}\text { Water jet } \\
\text { type }\end{array}$ & $\begin{array}{c}\text { Water } \\
\text { nozzle } \\
\text { diameter } \\
{[\mathbf{m m}]}\end{array}$ & $\begin{array}{c}\text { Focusing tube } \\
\text { diameter and } \\
\text { length }[\mathbf{m m}]\end{array}$ & $\begin{array}{c}\text { Water jet } \\
\text { traverse } \\
\text { speed } \\
{[\mathbf{m m} / \mathbf{m i n}]}\end{array}$ & $\begin{array}{c}\text { Water } \\
\text { pressure } \\
{[\mathbf{M P a}]}\end{array}$ & $\begin{array}{c}\text { Abrasive } \\
\text { mass flow } \\
\text { rate } \\
{[\mathbf{g} / \mathbf{m i n}]}\end{array}$ & $\begin{array}{c}\text { Jet incl. } \\
\text { angle } \\
{\left[{ }^{\circ}\right]}\end{array}$ & $\begin{array}{c}\text { Stand-off } \\
\text { distance } \\
{[\mathbf{m m}]}\end{array}$ \\
\hline $\begin{array}{c}\text { Continuous } \\
\text { plain water jet }\end{array}$ & $\begin{array}{c}0.33 \\
1.75\end{array}$ & - & $0-40$ & $30-300$ & - & $0-15$ & $\begin{array}{c}22.5- \\
1000\end{array}$ \\
\hline $\begin{array}{c}\text { Abrasive } \\
\text { water jet }\end{array}$ & 0.33 & $0.78 / 76$ & $0-40$ & $100-300$ & $0-300$ & $0-15$ & $22.5-$ \\
\hline $\begin{array}{c}\text { Pulsating } \\
\text { water jet }\end{array}$ & 1.75 & - & $0-1$ & $30-70$ & - & $2-8$ & 1000 \\
\hline
\end{tabular}

\subsection{Determination of suitable configuration}

Several options to remove surface layers of concrete specimens using the continuous highspeed water jets without and with addition of abrasives were tested. The first series of tests was performed from a relatively short distance. Other tests were carried out from long distances (Fig. 2).
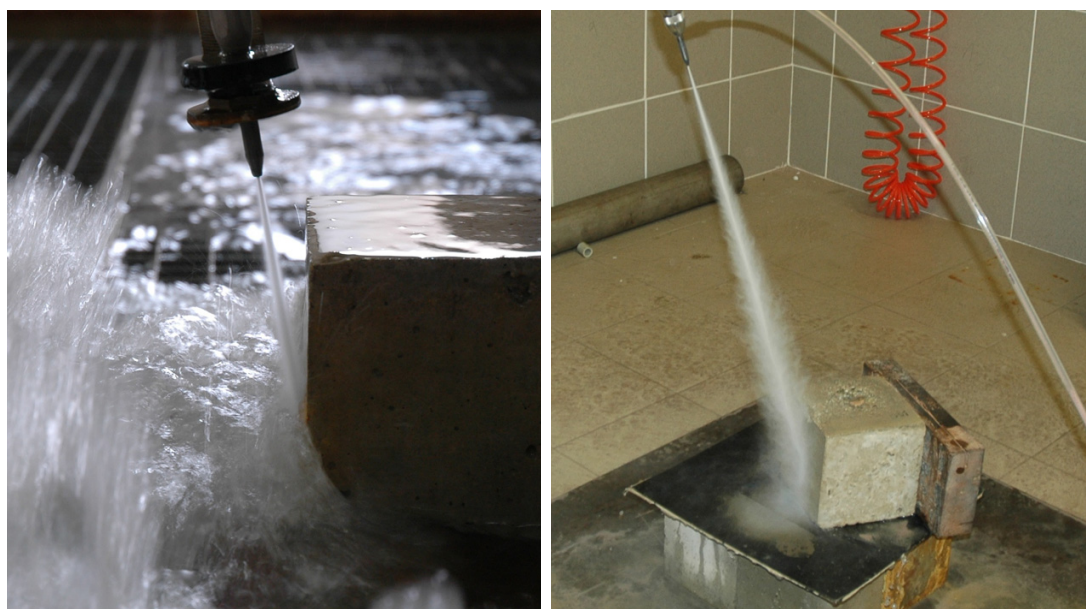

Fig. 2. Short (left) and long (right) stand-off distances of jet action

Concrete cubes of original strength of $40 \mathrm{MPa}$ placed in the $\mathrm{NaCl}$ solution for 6 months were selected as test specimens (chlorides can be commonly found in drinking water, besides, they can be of natural origin from rock subsoil. Their source is often waste water, leachates and sheet-washes from winter spreading of roads, etc). The water jet was generated by a standard JETS 7.5/60c high-pressure pump made by PTV Ltd. with a PTV diamond cutting head used for the abrasive water jet generation or, where appropriate, with a SLICE cutting head (water nozzle diameter of $0.33 \mathrm{~mm}$, focusing tube diameter of $0.78 \mathrm{~mm}$, focusing tube length of $76 \mathrm{~mm}$ ). In the case of the abrasive water jet, Australian garnet GMA concentrate with the grain size of mesh $80(0.18 \mathrm{~mm})$ was used.

By the water jet action from a short distance, various water jet inclinations to the impact area, jet position to the edge of the specimen and distance of the outlet of the focusing tube from the specimen (stand-off distance) were tested. Abrasive mass flow rate, water pressure in front of the nozzle and traverse speed of the cutting head over the specimen or, in the case of the stationary water jet, duration of the water jet action were also changed. 
By the water jet action from long distances, only the abrasive water jet was tested. The position of the jet impact on the specimen, stand-off distance, water jet inclination angle and water pressure in front of the nozzle were changed. Abrasive mass flow rate of $200 \mathrm{~g} \cdot \mathrm{min}^{-1}$ was constant and the tests were performed with a stationary water jet (i.e. without jetspecimen motion). The abrasive water jet impact on specimens always took 1 minute.

\subsection{Comparison of two different types of concretes}

At this stage, several options to remove surface layers of two different concrete mixtures using the continuous and pulsating water jets without abrasives and continuous water jets with abrasives were tested. Concrete tiles of various composition and properties (see Tables 2 and 3) - commonly used concrete of low strength (hereinafter referred to as concrete $I$ ) and progressive solid concrete (hereinafter referred to as concrete II) - served as test specimens. For reasons of clarity, the stage was further divided into a series of tests of concrete surfaces treatment by the abrasive water jet and a series of tests using the plain water jet (without the addition of abrasives).

Table 2. Composition of concrete mixtures

\begin{tabular}{|c|c|c|}
\hline Composition (per $\mathbf{1} \mathbf{~ m}^{\mathbf{3}}$ of fresh concrete) & $\begin{array}{c}\text { Concrete I } \\
\text { quantity } \mathbf{~ k g ]}\end{array}$ & $\begin{array}{c}\text { Concrete II } \\
\text { quantity } \mathbf{k g}]\end{array}$ \\
\hline Cement CEM I 42.5 R & - & 385 \\
\hline Cement CEM II/B-S 32.5 & 310 & - \\
\hline Aggregate 0-4 mm river sand & 1135 & 1110 \\
\hline Aggregate 4-8 mm coarse aggregate rounded gravel & 645 & 640 \\
\hline Water & 138 & 148 \\
\hline
\end{tabular}

Table 3. Properties of concrete mixtures after 28 days of curing

\begin{tabular}{|c|c|c|}
\hline & Concrete I & Concrete II \\
\hline Density $\left[\mathrm{kg} \cdot \mathrm{m}^{3}\right]$ & 2240 & 2250 \\
\hline Compressive strength $[\mathrm{MPa}]$ & 21 & 52 \\
\hline Flexural strength $[\mathrm{MPa}]$ & 2.2 & 6.1 \\
\hline
\end{tabular}

\subsubsection{Treatment of concrete surfaces using the abrasive water jet}

The tests were carried out using the abrasive water jet from a relatively short distance. The water jet was generated by a standard JETS 7.5/60c high-pressure pump on the basis of a pressure multiplier made by PTV s.r.o. with a SLICE cutting head used for the abrasive water jet generation (water nozzle diameter of $0.33 \mathrm{~mm}$, focusing tube diameter of $0.78 \mathrm{~mm}$, focusing tube length of $76 \mathrm{~mm}$ ). The Australian garnet GMA with the grain size of mesh 80 $(0.18 \mathrm{~mm})$ was used as abrasive material.

\subsubsection{Treatment of concrete surfaces using the plain water jet}

The series of tests were carried out using the water jet without abrasives from a long distance $(100 \mathrm{~mm})$. The water jet was generated by a Hammelmann HDP 253 high-pressure plunger pump. The cutting head was positioned using the ABB IRB 6640-180//2.55 Master robot. 
The water nozzle diameter of $1.75 \mathrm{~mm}$ was the same in all tests. Several tests were performed using the so-called pulsating water jet with a pulsation frequency of $20 \mathrm{kHz}$. According to our experience, this type of water jet is able to better simulate the abrasive wear of concrete surfaces.

First, grooves were performed with the jet slightly inclined to the testing surface. The jet moved only vertically from the bottom to the top at the speed of $1 \mathrm{~mm} \cdot \mathrm{min}^{-1}$. Subsequently, the surfaces were created using the cutting scheme in Fig. 3. The speeds used for the jet motion are presented in the figure in individual trajectories.

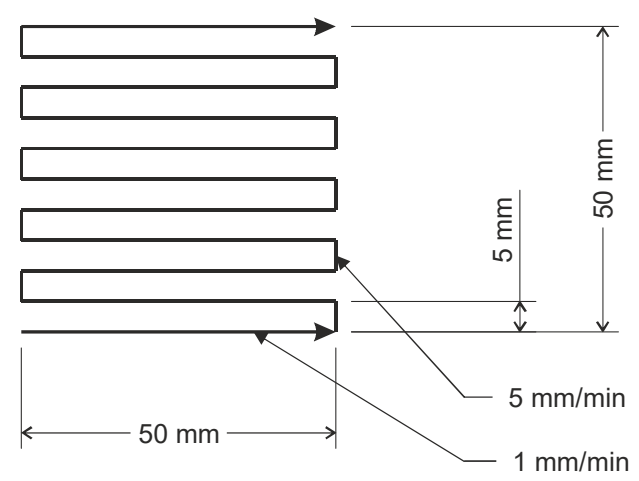

Fig. 3. Scheme of areal treatment of the surface

\section{Results and discussion}

In the following part, selected images of the treated surfaces (Figs. 4 - 10) including description and setting of parameters of the water jet technology for individual grooves/surfaces are shown.

The results show that abrasive water jets generated at high pressure and acting on the concrete surfaces from short distances are too aggressive and essentially cut the surface layers (Fig. 4) without washing out and taking away the structural elements of the surface layers, as is the case for the real erosion mechanism caused by rapidly flowing clean or polluted water. Unlike the abrasive jet, the plain water jet is partially reflected by the impact on the coarse aggregate after the hardened cement paste was removed. The jet bypasses the aggregate, thus changing its direction. However, erosion abilities of the plain water jet are several times less efficient compared to abrasive water jet (Fig. 5, surface 1), which is confirmed in [2].

When the abrasive water jet acts from large distances (up to $1 \mathrm{~m}$ ), a considerable amount of the water jet energy is lost and, above all, the flow is expanded and impacts on a larger surface area. This method better reflects the reality as regards the modelling of the effects of the impinging water (Fig. 6, left). However, when the abrasive water jet impacts on the surface at a small angle, the subsurface structural elements are rather cut-off than eroded (Fig. 6 , right). For the water jet without abrasives, the selected distance $(500-1000 \mathrm{~mm})$ is too long and the water jet is unable to leave any trace on the surface of the studied specimens within a specified period (1 $\mathrm{min})$. 


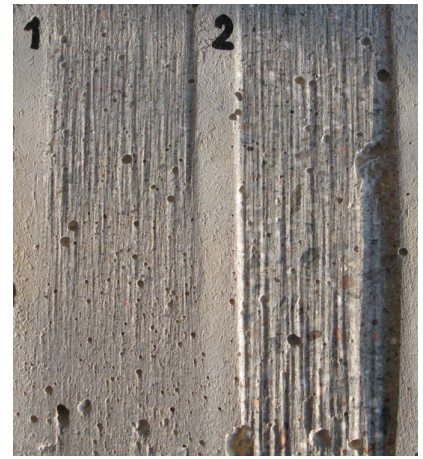

Fig. 4. Influence of water pressure and abrasive mass flow rate on the appearance of the treated surface (direction of jet action from top to bottom, jet traverse speed of 20 $\mathrm{mm} \cdot \mathrm{min}^{-1}$, jet inclination angle of $2^{\circ}$ relative to the surface, stand-off distance of $22.5 \mathrm{~mm}$;

surface 1 - water pressure of $100 \mathrm{MPa}$, abrasive flow rate of $100 \mathrm{~g} \cdot \mathrm{min}^{-1}$, surface 2 water pressure of $300 \mathrm{MPa}$, abrasive flow rate of $\left.300 \mathrm{~g} \cdot \mathrm{min}^{-1}\right)$

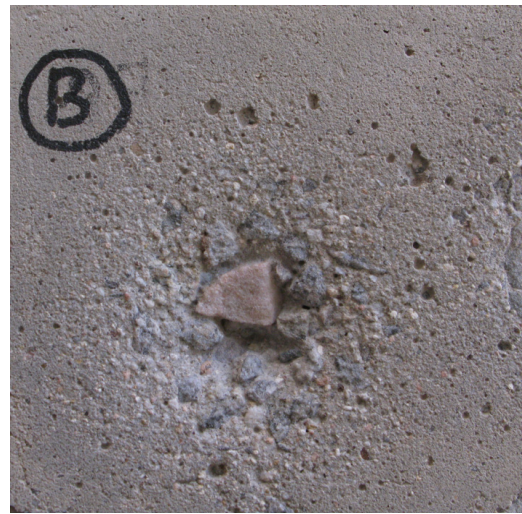

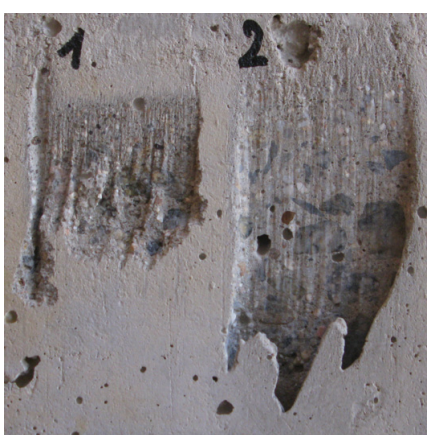

Fig. 5. Effect of abrasive presence on the appearance of the treated surface (direction of jet action - from top to bottom, jet traverse speed of $40 \mathrm{~mm} \cdot \mathrm{min}^{-1}$, jet inclination angle of $10^{\circ}$ relative to the surface, stand-off distance of

$22.5 \mathrm{~mm}$; surface 1 - plain water jet, water pressure of $300 \mathrm{MPa}$, surface 2 - abrasive water jet, water pressure of $200 \mathrm{MPa}$, abrasive flow rate of $200 \mathrm{~g} \cdot \mathrm{min}^{-1}$ )

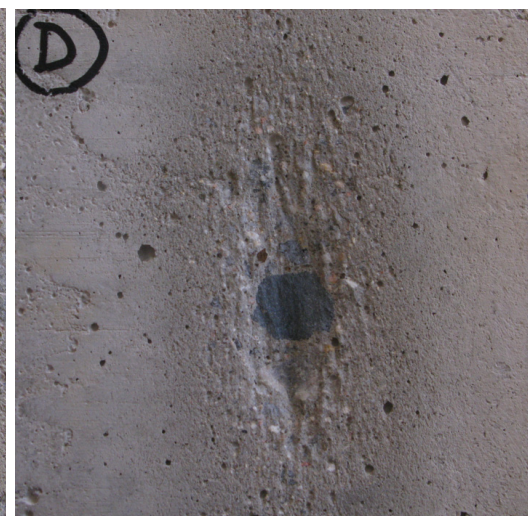

Fig. 6. Appearance of the concrete surface after the action of a stationary abrasive water jet from a long distance (water pressure of $300 \mathrm{MPa}$, abrasive flow rate of $200 \mathrm{~g} \cdot \mathrm{min}^{-1}$, exposure time of the jet acting on surface - 1 min; left - jet inclination angle - perpendicular to the surface, stand-off distance of $1000 \mathrm{~mm}$, right - jet inclination angle of $15^{\circ}$ relative to the surface, stand-off distance of $500 \mathrm{~mm}$ )

Comparison of two different types of concretes shows that less solid concrete is less resistant to the high-speed water jet impact - whether it is the water jet without or with addition of abrasives. Although the abrasive water jet easily penetrated in the surface layers of concretes, the aggregate in the concrete structure was cut (Fig. 7) due to the high speed and energy of abrasive particles, as stated in [25]. Again, this method does not correspond to the resulting degradation of real concrete structures by erosion and abrasion. In this regard, tests using the water jets without abrasives - whether continuous or pulsating - better reflect the reality. The pulsating water jet is more efficient than the continuous water jet (compare left and right surfaces in Fig. 8) [26]. The fine-tuning of the required disintegration and especially the elimination of cutting into the material depend on the water jet parameters setting. 

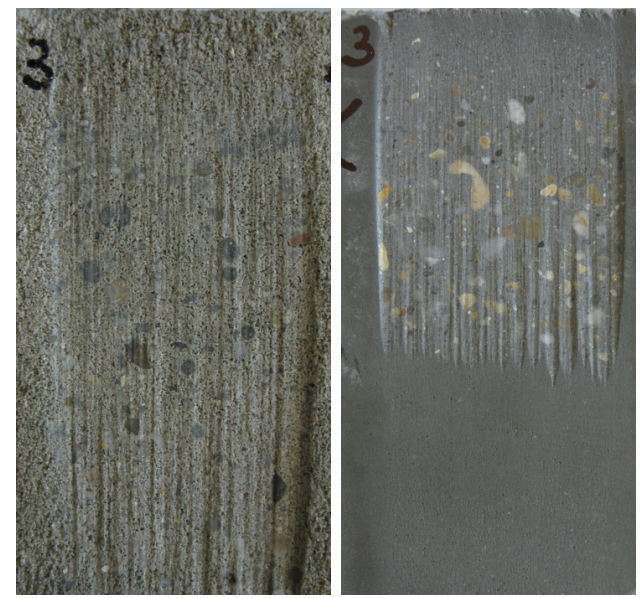

Fig. 7. Influence of concrete type on the appearance of the treated surface (direction of jet action - from top to bottom, water pressure of 110 $\mathrm{MPa}$, water nozzle diameter of $0.33 \mathrm{~mm}$, focusing tube diameter of $0.78 \mathrm{~mm}$, jet traverse speed of 5 $\mathrm{mm} \cdot \mathrm{min}^{-1}$, jet inclination angle of $2^{\circ}$ relative to the surface, stand-off distance of $12 \mathrm{~mm}$, abrasive flow rate of $50 \mathrm{~g} \cdot \mathrm{min}^{-1} ;$ left - concrete I, right concrete II)
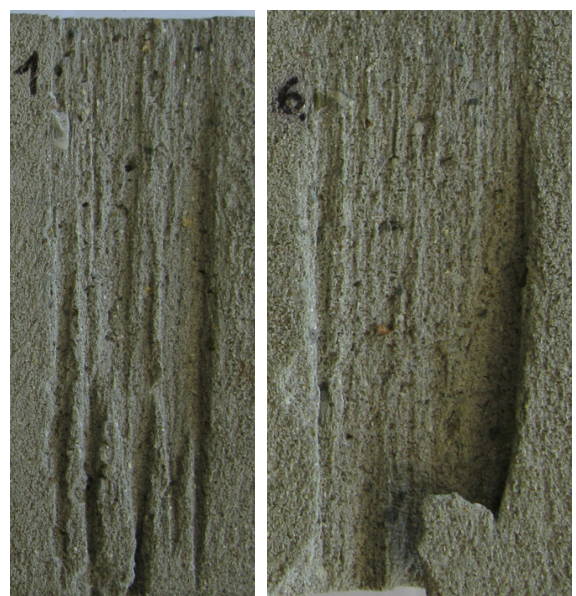

Fig. 8. Influence of pulsations in jet on the appearance of the treated surface (direction of jet action - from top to bottom, water pressure of $70 \mathrm{MPa}$, water nozzle diameter of $1.75 \mathrm{~mm}$, jet traverse speed of $1 \mathrm{~mm} \cdot \mathrm{min}^{-1}$, jet inclination angle of $8^{\circ}$ relative to the surface, stand-off distance of $100 \mathrm{~mm}$; jet motion according to scheme in Fig. 3; left surface - continuous jet, right surface pulsating jet)

When a solid concrete was disintegrated by the water jets without abrasives with appropriately set parameters, the water jets did not penetrate into the structure of concrete surface layers, if the concrete surface was smooth. However, on the rough surface (Fig. 9), the material was disintegrated and removed due to the cavitation caused by the water flowing over the surface of the studied specimen [27].
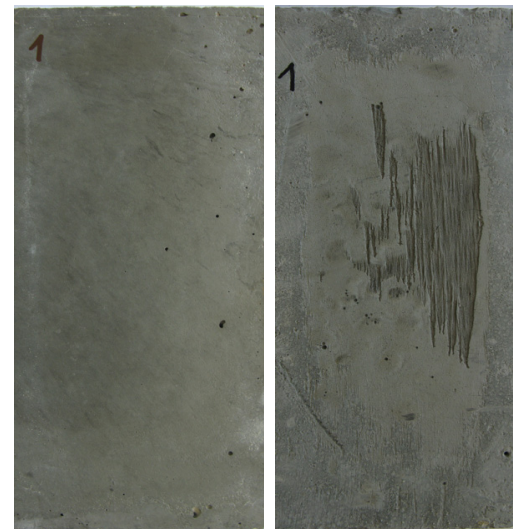

Fig. 9. Influence of surface roughness on the appearance of the treated surface (direction of jet action - from top to bottom, plain water jet, water pressure of $30 \mathrm{MPa}$, water nozzle diameter of $1.75 \mathrm{~mm}$, jet traverse speed of $1 \mathrm{~mm} \cdot \mathrm{min}^{-1}$, jet inclination angle of $8^{\circ}$ relative to the surface, stand-off distance of $100 \mathrm{~mm}$, jet motion according to scheme in Fig. 3; left - smooth surface, right-rough surface). 
Regading suitable water jet motion, the impact of a narrow, non-moving jet causes a deep groove on the studied surface. The water jet is thus not appropriate for the simulation of the real degradation process. It is more appropriate if the water jet moves along the surface perpendicular to the direction of the jet impact (e.g. Fig. 10). The composite motion of the water jet along the surface as seen in Fig. 3 is considered as the most suitable

Another possible option is the use of the so-called flat water jets, which spread the energy over a larger area due to a special nozzle [28]. However, this method was not tested during the experiments described. Due to the limited scope of the article, there is also no quantification of the obtained data describing the surface properties of concrete, statistical processing, etc. These data will be the subject of further publications by the authors of the article.

\section{Conclusion}

On the basis of an experimental program focused on finding an appropriate configuration of the high-speed water flow for an accelerated simulation of erosion failure of concrete surfaces exposed in practice to fast-flowing liquids, the following was found.

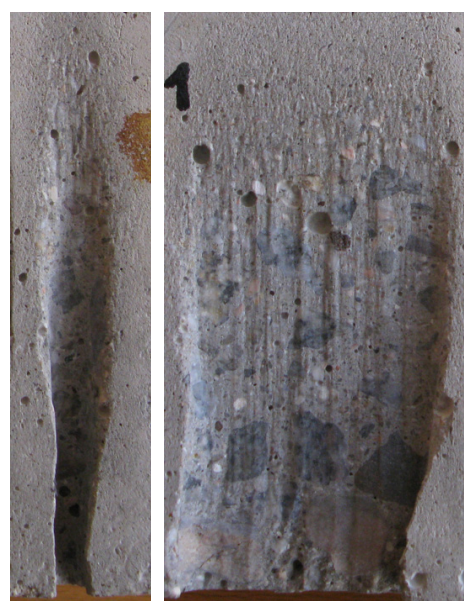

Fig. 10. Influence of jet motion along the concrete surface (direction of jet action - from top to bottom, abrasive water jet, water pressure of $300 \mathrm{MPa}$, water nozzle diameter of $0.33 \mathrm{~mm}$, focusing tube diameter of $0.78 \mathrm{~mm}$, focusing tube length of $76 \mathrm{~mm}$, jet inclination angle of $10^{\circ}$ relative to the surface, stand-off distance of $22.5 \mathrm{~mm}$, abrasive flow rate of $300 \mathrm{~g} \cdot \mathrm{min}^{-1}$; left groove - stationary jet, surface 1 - moving jet, traverse speed of $40 \mathrm{~mm} \cdot \mathrm{min}^{-1}$ )

The high-speed water jet technology is a suitable tool for simulation of erosion and abrasive wear of concretes. The abrasive water jet impacting on the surface from short distances is inappropriate for the simulation of real degradation processes, as the water jet cuts the structural elements of concretes, the aggregate included. However, this type of the jet can be used to simulate the impacting flow, but only if acting from long distances. The plain water jet impacting on the surface at a small angle is, on the contrary, a suitable simulation tool. However, it is desirable to move the plain water jet along the studied surface according to the appropriate scheme as the jet acts at the point of impact only. More efficient than the continuous plain water jet is the pulsating water jet, which shortens the simulation times. Simulating water jet parameters should be particularly set based on the appearance and the state of the real-degraded surfaces so that the result reflects the reality. Generally, rough surfaces are disintegrated more easily and quickly compared to the smooth surfaces due to the turbulence and cavitation caused by the flows of fast-flowing liquids along the surfaces. 
This work was supported by grant of the Czech Science Foundation (18-25035S) and by project of the Institute of Clean Technologies for Mining and the Utilization of Raw Materials for Energy Use Sustainability program, reg. no. LO1406 financed by the Ministry of Education, Youth and Sports of the Czech Republic.

\section{References}

1. D.A. Summers, Waterjetting Technology. E \& FN Spon, London, (1995)

2. A.W. Momber, Hydrodemoliton of Concrete Surfaces and Reinforced Concrete Structures. Elsevier, Oxford, (2005)

3. A.W. Momber (ed.), Water Jet Application in Construction Engineering. A.A.Balkema, Rotterdam, (1998)

4. L.H. McCurrich, R.D. Browne, Application of water jet cutting technology to cement grouts and concrete. In 1st Int. Symp. Jet Cutting Technol. Eds. T. E. Brock, A. Richardson. BHRA, Cranfield. G7/69-G7/91 (1972)

5. R. Medeot, History, Theory, and Practice of Hydrodemolition. In 5th American Water Jet Conference, Toronto, Canada. U.S: Water Jet Technology Association. (1989)

6. J. Silfwerbrand, Improving concrete bond in repaired bridge decks. Concrete Int., 12(9), 61-66 (1990)

7. A. Momber, R. Kovacevic, Fundamental investigations on concrete wear by highvelocity water-flow. Wear 177(1), 55-62 (1994)

8. A.W. Momber, R. Kovacevic, J. Ye, The fracture of concrete due to erosive wear by high-velocity water-flow. Tribology transactions 38(3), 686-692 (1995)

9. A.W. Momber, A probabilistic model for the erosion of cement-based composites due to very high-speed hydro-abrasive flow. Wear 368, 39-44 (2016)

10. X.G. Hu, A.W. Momber, Y.G. Yin, Hydro-abrasive erosion of steel-fibre reinforced hydraulic concrete. Wear 253, 848-854 (2002)

11. X.G. Hu, A.W. Momber, Y. Yin, Erosive wear of hydraulic concrete with low steel fiber content. Journal of hydraulic engineering 132, 1331-1340 (2006).

12. ACI Committee 210. Erosion of Concrete in Hydraulic structure (ACI 210R-03). American Concrete Institute, Farmington Hill, MI (2003)

13. E.K. Horszczaruk, Hydro-Abrasive Erosion of High Performance Fibre-Reinforced Concrete. Wear 267(1-4), 110-115 (2009)

14. Y.W. Liu, S.W. Cho, T.H. Hsu, Impact abrasion of hydraulic structures concrete, Journal of marine science and technology 20(3), 253- 258 (2012)

15. A.W. Momber, R.S. Mohan, R. Kovacevic, On-line analysis of hydro-abrasive erosion of pre-cracked materials by acoustic emission. Theoretical and Applied Fracture Mechanics 31, 1-17 (1999)

16. A.W. Momber, R. Kovacevic, Accelerated high speed water erosion test for concrete wear debris analysis. Tribology Transactions 39(4), 943-949 (1996)

17. J. Foldyna, P. Jekl, L. Sitek, Possibilities of utilization of modulated jets in rock cutting. Proc. of the 1st Int. Conf. Mining Techniques, Filipowicz, Feliks (eds.), AGH, 85-96 (2001)

18. L. Sitek, Analysis of the process of rock disintegration by high-speed water jets based on laboratory measurements. Ph.D. Thesis, VŠB - Technical University Ostrava (2000) 
19. P. Martinec, J. Foldyna, L. Sitek, J. Ščučka, J. Vašek, Abrasives for AWJ cutting. INCO -COPERNICUS No. IC 15-CT98-0821. Institute of Geonics (2002)

20. M. Zeleňák, J. Foldyna, M. Linde, F. Pude, T. Rentsch, J. Fernolendt, H.U. Poort, Measurement and analysis of abrasive particles velocities in AWSJ. Procedia Engineering, 149, 77-86 (2016)

21. M. Zeleňák, J. Ščučka, K. Souček, Velocity measurements on continuous micro water jet using fluorescent PMMA seeding particles. Proceedings of the $5^{\text {th }}$ Int. Conf. Water Jet 2017, Klichová, Sitek (eds.), Institute of Geonics, 221-231 (2017)

22. M.M. Vijay, Power of pulsed liquid jets. In: Geomechanics 93 Z. Rakowski, Editor. A. A. Balkema Publishers, Rotterdam, Netherlands, 265-274 (1994)

23. M.M. Vijay, J. Foldyna, J. Remisz. Ultrasonic Modulation of High-Speed Water Jets. In: Geomechanics 93 Z. Rakowski, Editor. A. A. Balkema Publishers, Rotterdam, Netherlands. 327-332 (1994)

24. J. Foldyna, L. Sitek, P. Jekl, D. Nováková, Measurement of force effects of modulated jet. Proceedings of the 39th Int. Conf. Experimental Stress Analysis, Jírová, Jiroušek, Kult (eds.), CTU in Prague, 63-68 (2001)

25. A.W. Momber, Effects of erodent flow energy and local exposure time on the erosion of cement-based composites at high-speed hydro-abrasive flow. Wear 378-379, 145-154 (2017)

26. J. Foldyna, L. Sitek, P. Martinec, J. Ščučka, P. Jekl, M. Młynarczuk, Rock cutting by pulsing water jets. In: Eurock 2005 - Impact of Human Activity on the Geological Environment. P. Konečný Editor, A. A. Balkema Publishers, Leiden, Netherlands, 129$134(2005)$

27. A.W. Momber, Short-time cavitation erosion of concrete, Wear 241, 47-52 (2000)

28. L. Sitek, L. Bodnárová, J. Válek, M. Zeleňák, J. Klich, J. Foldyna, M. Novotný, Effects of water jet on heat-affected concretes. Procedia Engineering 57, 1036-1044 (2013) 